\title{
Spanish validation and cultural adaptation of the Five-Word Test for the detection of the neurocognitive disorder in older adults
}

\author{
Sara Gloria Aguilar-Navarro, 1,2 Alberto José Mimenza-Alvarado, 1,2 Rafael Martínez-Sánchez,' Silvia Mejía-Arango, ${ }^{3,4}$ \\ Lidia Gutiérrez-Gutiérrez, ${ }^{5}$ José Alberto Ávila-Funes 1,6
}

Departamento de Geriatría, Instituto Nacional de Ciencias Médicas y Nutrición Salvador Zubirán, Ciudad de México, México.

2 Posgrado en Neurología Geriátrica, Instituto Nacional de Ciencias Médicas y Nutrición Salvador Zubirán, Ciudad de México, México.

Departmento de Estudios Poblacionales, El Colegio de la Frontera Norte, Tijuana, Baja California, México.

${ }^{4}$ Sealy Center on Aging, University of Texas Medical Branch.

${ }^{5}$ Departamento de Neurología y Psiquiatría, Instituto Nacional de Ciencias Médicas y Nutrición Salvador Zubirán, Ciudad de México, México.

6 Univ. Bordeaux, Inserm, Bordeaux Population Health Research Center, Bordeaux, France.

\section{Correspondence:}

Sara G. Aguilar Navarro

Servicio de Geriatría Instituto

Nacional de Ciencias Médicas y

Nutrición Salvador Zubirán.

Vasco de Quiroga 15, Belisario

Domínguez Sección XVI, 14080

Tlalpan, Ciudad de México, México.

Phone: +52 (55) 5487-0900 ext.

5710

Email: sgan30@hotmail.com

Received: 13 January 2019

Accepted: 16 October 2019

Citation:

Aguilar-Navarro, S. G., Mimenza-Alvarado A. J. Martínez-Sánchez, R.

Mejía-Arango, S. Gutiérrez-Gutiérrez,

L., \& Ávila-Funes, J. A. (2019). Span-

ish validation and cultural adaptation

of the Five-Word Test for the detection

of the neurocognitive disorder in older

adults. Salud Mental, 42(6), 28 1-287.

DOI: $10.17711 /$ SM.0185-3325.2019.037

\begin{abstract}
Introduction. "Episodic" memory problems are common in people with cognitive impairment due to Alzheimer's disease and related disorders. Dubois et al. developed the Five-Word Test (5WT) to evaluate episodic memory, which has proved to be an easy and valid test for identifying cognitive disorders. However, its validation and cultural adaptation from French to Spanish has not been undertaken and its usefulness in Mexican population is unknown. Objective. Validation and cultural adaptation of the 5WT for screening minor and major neurocognitive disorder (ND) in Mexican older adults with probable Alzheimer's disease. Method. Two hundred and fifteen participants (70 cognitively healthy subjects, 73 with minor ND and 72 with major ND were included). The cognitive status (gold standard) was determined using current clinical criteria and neuropsychological evaluation. The Spearman coefficient, ROC curve, and multinomial logistic regression models were used to determine the concurrent validity of the 5WT. Results. The correlation between the 5WT and the Mini-Mental State Exam (MMSE) was .58, whereas for the clock face test it was $-.37(p<.001)$. The area under the 5WT curve was $.97(95 \% \mathrm{Cl}[.94, .99])$, with a cut-off point of $\leq 16 / 20$ for the diagnosis of major ND (89\% sensitivity, $98 \%$ specificity) and $.77(95 \% \mathrm{Cl}[.70, .85])$ for minor ND with a cut-off point of $\leq 18 / 20(66 \%$ sensitivity, $77 \%$ specificity). Discussion and conclusion. Since the $5 \mathrm{WT}$ is a simple, valid instrument for the identification of neurocognitive disorders like Alzheimer's disease, it could be a practical screening test.
\end{abstract}

Keywords: Neurocognitive disorder, Alzheimer's disease, Five-Word Test, screening, older adult.

\section{RESUMEN}

Introducción. Los problemas de la memoria "episódica" son comunes en las personas con deterioro cognitivo tipo Alzheimer. Dubois et al. desarrollaron la Prueba de Cinco Palabras (P5P) para evaluar la memoria episódica, la cual ha demostrado ser sencilla y válida para identificar trastornos cognitivos. Sin embargo, su validación y adaptación cultural del francés al español no se ha realizado y se desconoce su utilidad en población mexicana. Objetivo. Validación y adaptación cultural de la P5P para el tamizaje del trastorno neurocognitivo (TNC) menor y mayor en adultos mayores mexicanos con probable enfermedad de Alzheimer. Método. Participaron 215 participantes ( 70 cognitivamente sanos, 73 con TNC menor y 72 con TNC mayor. El estado cognitivo (estándar de oro) se determinó mediante los criterios clínicos vigentes y de evaluación neuropsicológica. El coeficiente de Spearman, la curva ROC y modelos de regresión logística multinomial se utilizaron para determinar la validez concurrente de la P5P. Resultados. La correlación entre la P5P y el MMSE fue de .58, mientras que para la prueba de reloj fue de -.37 ( $p<.001)$. El área bajo la curva de la P5P fue .97 (IC 95\% [.94, .99]), con un punto de corte $\leq 16 / 20$ para el diagnóstico del TNC mayor (sensibilidad: $89 \%$, especificidad: $98 \%$ ) y de .77 (IC $95 \%$ $[.70, .85])$ para el TNC menor con un punto de corte $\leq 18 / 20$ (sensibilidad: $66 \%$, especificidad: $77 \%$ ). Discusión y conclusión. La P5P es un instrumento válido y simple para identificar de trastornos neurocognitivos de tipo Alzheimer por lo que podría ser una prueba práctica para uso en el tamizaje.

Palabras clave: Trastorno neurocognitivo, enfermedad de Alzheimer, Prueba de las Cinco Palabras, tamizaje, adulto mayor. 


\section{INTRODUCTION}

Population aging is associated with an increase in cognitive impairment cases. In Latin America, a prevalence of 11\% is estimated in adults aged 60 and over (Consejo Nacional de Población, 2013; Organización Panamericana de la Salud, 2001) compared with $8 \%$ in Mexico (Mejía-Arango, Miguel-Jaimes, Villa, Ruiz-Arregui, \& Gutiérrez-Robledo, 2007; Wong, Espinoza, \& Palloni, 2007). The Dementia Research Group 10/66 multicentric, population-based studies on adults aged 65 and over found an $8.6 \%$ prevalence of dementia for Mexico in urban areas and an $8.5 \%$ prevalence in rural areas, both adjusted for sex, age, and educational attainment (Rodriguez et al., 2008). Studies with data on dementia incidence in Mexico include the ENASEM (Encuesta Nacional de Salud y Envejecimiento en México) which, after a two-year follow-up (2001-2003), estimated an overall incidence rate of 27.3 cases per 1000 person-years (Mejía-Arango \& Gutierrez-Robledo, 2011). The 10/66 GID study also has estimates of dementia incidence in Mexican population based on an initial three-year follow-up. It reports an overall incidence of 30.4 cases per 1 000 person-years (Prince et al., 2012). Despite its higher incidence, however, less than half of the cases are diagnosed (particularly Alzheimer's disease) (Wong, Michaels-Obregon, \& Palloni, 2015). Among other factors, underestimation of cognitive impairment or dementia cases is due to the lack of systematic screening owing to limited consultation lengths (Navarrete \& Rodríguez-Leyva, 2003), the absence of validated, easily-applied tools for timely detection and the minimization of the importance of cognitive and functional changes that occur in older adults (Bush, Kozak, \& Elmslie, 1997; Doraiswamy, Steffens, Pitchumoni, \& Tabrizi, 1998; Grober, Buschke, Crystal, Bang, \& Dresner, 1998). However, early diagnosis of these diseases continues to be very important since it enables measures to be implemented to maintain patient safety and support and to educate caregivers, plan for the future and initiate appropriate pharmacological and non-pharmacological treatment.

"Episodic" memory problems are common in people with cognitive impairment due to Alzheimer's disease and tend to appear early. Moreover, their effect on memory-which translates hippocampal damage-is key to establishing an early diagnosis of Alzheimer's disease (AD), the most frequent form of major neurocognitive disorder (ND) in Mexico and the world (American Psychiatric Association, 2014; Dubois et al., 2010; Grober et al., 2016). A simple test evaluating episodic memory could therefore be useful in clinical practice. So, Dubois et al. (2002) developed the Five-Word Test (5WT) to assess verbal episodic memory to obtain a cortical neuroanatomical profile. This tool has proven to be simple and valid for the identification of cognitive disorders such as Alzheimer's disease. However, its application outside its country of origin is limited. Accordingly, the main objective of the present study was to determine the concurrent validity of the 5WT for screening minor and major ND and culturally adapt it for Mexican older adults.

\section{MATERIAL AND METHODS}

\section{Study design}

Validation and cultural adaptation study conducted between March 2017 and March 2018 at the Memory Clinic of a tertiary-level university hospital in Mexico City.

\section{Participants}

The study included men and women aged 60 and older, who lived in community and agreed to participate after signing an informed consent form. The sample size was calculated from the nomogram proposed by Carley, Dosman, Jones, and Harrison (2005), where a prevalence of ND of over $8 \%$, confidence intervals (CI) of $95 \%$ and a test specificity of $90 \%$ were considered. Accordingly, at least 70 participants were required for each group with a 5\% alpha and $80 \%$ power. Participants completed a standardized clinical and neuropsychological interview for age, sex, and educational attainment conducted by a specialist in geriatrics and/or neurology. The Mini-Mental State Examination (MMSE) (Folstein, Folstein, $\&$ McHugh, 1975) with a score of 0-30, where a higher score indicates better cognitive functioning and the clock face drawing test with a score of $0-14$, where a lower score indicates better cognitive functioning (Aguilar-Navarro et al., 2018; Eknoyan, Hurley, \& Taber, 2012) were applied.

\section{Clinical diagnosis: Minor, major ND, and cognitively Healthy group}

A diagnosis of Alzheimer's disease or ND was established on the basis of the criteria of the National Institute of Neurological and Communicative Disorders and Stroke and the Alzheimer's Disease and Related Disorders Association NINCDS/ADRDA (McKhann et al., 1984), and the Clinical Dementia Rating Scale (CDR; Morris, 1993). The criteria established in the Diagnostic and Statistical Manual of Mental Disorders, Fifth Edition (DSM-5, American Psychiatric Association (2014) were also used to establish a diagnosis of minor ND. The comparison or cognitively healthy group, comprising those with cognitively normal performance, who had no subjective memory complaints, scored over 26 in the MMSE and obtained a CDR $=0$.

Functional status was assessed using the Katz Index with a score of 0-6, where a higher score indicated greater independence for basic activities of daily living (BADLs; Katz \& Akpom, 1976) and the Lawton \& Brody Index with a score of $0-8$, where a higher score indicated greater inde- 
pendence in instrumental activities of daily living (IADLs; Lawton \& Brody, 1969).

Exclusion criteria were: fewer than or equal to two years of schooling, presenting heart, liver, or kidney disease, cancer or another uncontrolled systemic disease, or a severe visual or auditory deficit in the clinical evaluation, which would make it impossible to apply the tests, presence of serious neurological diseases (toxic, metabolic, infectious), significant depressive symptomatology with a score of $>5 / 15$ on the Geriatric Depression Scale (Sheikh \& Yesavage, 1986), vascular and/or mixed dementia, and severe major ND according to the Clinical Dementia Rating Scale (CDR; Morris, 1993).

\section{Five-word test (5WT)}

\section{Cultural adaptation of the $5 \mathrm{WT}$}

The cultural adaptation of this test was undertaken by linguistic experts from El Colegio de México. Five nouns from the Spanish language (Mexico) were selected, with a similar meaning in different regions of the country, with a length of two to three syllables and beginning with different letters of the alphabet. The five words belong to different semantic categories (Bus - transport, Glove - clothing, Pigeon - animal, Tooth - body part, Market - place). Understanding of the chosen words was tested in small groups of older adult volunteers who attended the memory clinic of the study site.

The 5WT involves two general stages: immediate recall and deferred recall. The first stage includes a Registration Phase, in which words printed on a sheet are presented (written in capital letters, with a 36-point font size): "Read this list of five words aloud and try to learn them because I will ask you for them later." After the list had been read and with the list still in front of the patients, they are asked to point to and name each of the words, indicating the semantic category to which they belong. For example, "Could you point to and say which of these words is an animal?" and so on with each of them in the following order: animal, place, means of transport, body part, and clothing (in order to create a semantic association between the word and the category to which they belonged). This is followed by an Immediate Recall Phase in which, once the list has been removed, participants are asked to say the words they have just read in the order they remember them. The number of correctly remembered words constitutes the Immediate Free Recall score (IFR). Afterwards, if a word is not remembered, the examiner provides the semantic category to facilitate recall. The number of words recalled by using the semantic category constitutes the Immediate Recall with Clue (IRC) score. If the person fails to remember a particular word even with the semantic clue, its learning must be reinforced by showing him/her the list again and pointing to each unlearned word, naming both the semantic category to which they belonged and the word itself, for example, "The animal's name is a dove." The list is removed again, and the participant is asked about the word using its semantic clue to ensure its coding, for example, "What was the name of the animal?" This step can be repeated up to three times if necessary. Words learned in this way are not included in the score for this phase.

Before moving on to the second stage of the 5WT, a nonverbal cognitive task (such as the clock face drawing test) is performed, which acts as interference for three to five minutes. Participants subsequently proceed to the second stage.

During this stage, participants are asked to recall the five words on the list. The number of correctly remembered words constitutes the Deferred Free Recall (DFR) score. For each word not spontaneously recalled, participants are prompted with its semantic clue. The number of words recalled using the semantic category constitutes the Deferred Recall with Clue (DRC) score. This marks the end of the test.

Three scores can be estimated from the 5WT: a Free Recall Score (FRS) by adding the IFR + DFR, a Total Recall Score (TRS) from the sum of IFR + IRC + DFR + DRC (both scores with a range of 0 to 10 ), and a Weighted Total Score (WTS) calculated by using the following formula: $[($ IFR $\times 2)+$ IRC $]+[($ DFR $\times 2)+$ DRC $]($ range 0 to 20$)$ (Croisile, Astier, \& Beaumont, 2007). The estimated average time of application of the 5WT is five minutes.

\section{Statistical analysis}

A descriptive analysis of the sample was performed, registering frequencies, percentages, means, and standard deviations (SD) according to the type of variable. For the comparative analysis of the categorical variables, the $\mathrm{Chi}^{2}$ test and the Kruskal-Wallis test were used for continuous variables. The concurrent validity was established by comparing the 5WT with the MMSE and the clock face drawing test and the Spearman correlation coefficient estimate $\left(\mathrm{r}_{\mathrm{s}}\right)$.

Multinomial logistic regression models were constructed to determine the discriminative capacity of the 5WT of the three groups included, considering the effect of participants' age, sex, and educational attainment. To establish the accuracy of the 5WT for the diagnosis of minor and major ND, the area under the curve was estimated, as well as its sensitivity and specificity. A $p$ value of less than .05 was considered statistically significant. The analyses were performed using SPSS Statistics 20.0 (SPSS Inc., Chicago, Illinois). The protocol was approved by the ethics committee of the institution.

\section{Ethical considerations}

The study was conducted in accordance with the ethical standards of the institutional Human Experimentation Committee, the World Medical Association, and the Helsinki Declaration. 
Table 1

Comparative analysis between the three cognitive groups by sociodemographic and health variables

\begin{tabular}{lcccc}
\hline & \multicolumn{1}{c}{ CH } & Minor ND & Major ND & \\
& \multicolumn{1}{c}{$n=70$} & $n=73$ & $n=72$ & $p$ \\
\hline Age in years, average (SD) & $75.1(6.9)^{\mathrm{a}}$ & $82.3(7.7)^{\mathrm{b}}$ & $79.2(7.2)^{\mathrm{c}}$ & $\leq .001^{\mathrm{a}, \mathrm{b}, \mathrm{c}}$ \\
Female gender (\%) & 65.7 & 53.42 & 58.3 & .324 \\
Schooling in years, average (SD) & $10.1(5.1)$ & $10.6(5.6)$ & $8.9(4.8)$ & .118 \\
GDS, mean (SD) & $2.6(2.7)$ & $2.93(2.0)$ & $3.1(1.6)$ & .318 \\
MMSE, mean (SD) & $27.7(1.8)^{\mathrm{a}}$ & $26.1(3.1)^{\mathrm{b}}$ & $20.7(3.9)^{\mathrm{c}}$ & $\leq .001$ \\
Clock face test, mean (SD) & $1.0(1.7)$ to & $2.2(1.98)^{\mathrm{b}}$ & $4.2(3.5)^{\mathrm{c}}$ & $\leq .001$ \\
Five-word test & & & & \\
Free recall score, mean (range) & $8.8(7-10)^{\mathrm{a}}$ & $6.9(4-9)^{\mathrm{b}}$ & $4.1(2-6)^{\mathrm{c}}$ & $\leq .001$ \\
Total recall score, mean (range) & $9.7(9-10)^{\mathrm{a}}$ & $8.8(7-10)^{\mathrm{b}}$ & $6.5(4-9)^{\mathrm{c}}$ & $\leq .001$ \\
Weighted total score, mean (range) & $18.6(16-20)^{\mathrm{a}}$ & $15.7(12-19)^{\mathrm{b}}$ & $10.7(6-15)^{\mathrm{c}}$ & $\leq .001$ \\
\hline
\end{tabular}

Notes: CH:Cognitively health, ND:Neurocognitive Disorder, GDS:Geriatric Depression Scale, MMSE:Mini-Mental State Examination.

Data are presented as means, ranges and standard deviations.

The analysis shows the differences between groups using the ANOVA, post-hoc DSM test.

${ }^{a} p \leq .001$ between control and minor ND;

${ }^{\mathrm{b}} p \leq .001$ between control and major ND;

${ }^{c} p \leq .001$ between minor and major ND.

\section{RESULTS}

Of the 215 participants included, 70 were classified as cognitively healthy $(\mathrm{CH}), 73$ with minor ND and 72 with major ND. The average age was 78.9 years $(S D=7.8), 59 \%$ were women and average educational attainment was 9.9 years $(S D=5.2)$. Although participants with minor ND were older than the other two groups, there was no statistically significant difference with respect to sex or educational at- tainment. As expected, participants with minor and major ND performed worse on all cognitive tests compared with the $\mathrm{CH}$ group (both $p \leq .001$ ). The sociodemographic data and cognitive performance of the participants are shown in Table 1.

A moderate positive correlation was observed between the 5WT score and the MMSE $\left(\mathrm{r}_{\mathrm{s}}=.58 ; p<.001\right)$ and a low negative correlation between the 5WT and the clock face drawing test $\left(\mathrm{r}_{\mathrm{s}}=-.37 ; p<.001\right)$.

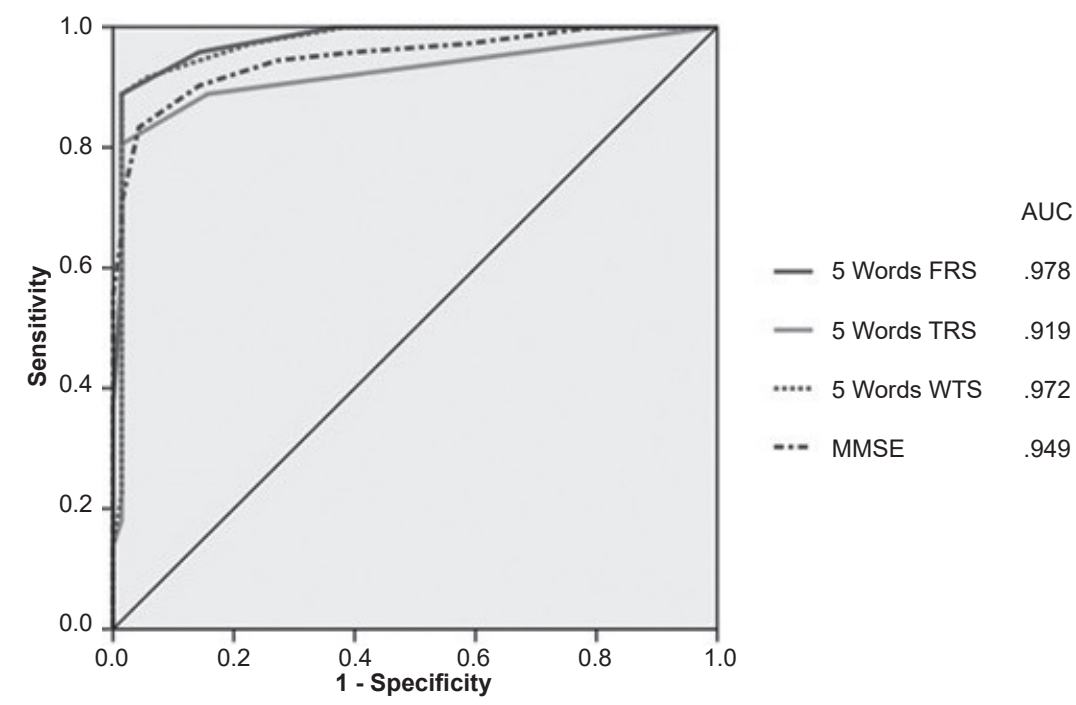

Figure 1. The area under the curve of the Mini-Mental State Examination (MMSE) and the free recall score (FRS), the total recall score (TRS), and the weighted total score (WTC) of the Five-Word Test for the diagnosis of major ND compared to cognitively healthy participants. AUC indicates the area under the curve. 


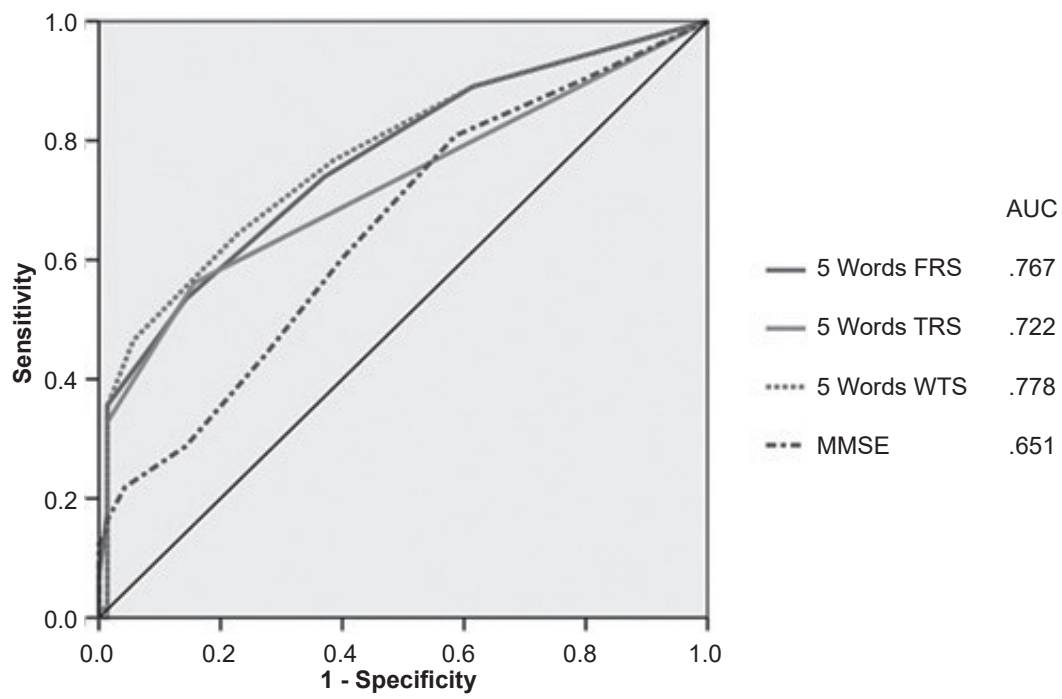

Figure 2. The area under the curve of the Mini-Mental State Examination (MMSE) and the free recall score (FRS), the total recall score (TRS), and the weighted total score (WTC) of the Five-Word Test for the diagnosis of minor ND compared to cognitively healthy participants. AUC indicates the area under the curve.

The multinomial logistic regression showed that the various 5WT scores (FRS, TRS and WTS) discriminated between the different groups $(p<.001)$ even after considering the effect of age, sex, and educational attainment.

Finally, the area under the curve for the FRS, TRS, and WTS was estimated. This was .97 (95\% CI $[.94, .99])$ for the WTS with a cut-off point of $\leq 16,89 \%$ sensitivity and 98\% specificity for the diagnosis of major ND (Figure 1).

Conversely, for the diagnosis of minor ND, the area under the WTS curve was smaller, .77 (95\% CI $[.70, .85])$ with a cut-off point of $\leq 18,66 \%$ sensitivity and $77 \%$ specificity (Figure 2).

Finally, Table 2 shows and highlights the sensitivity and specificity for the detection of major ND and minor ND with the optimal cut-off values of FRS, TRS, and WTS.

\section{DISCUSSION AND CONCLUSION}

The present study shows that the 5WT can be culturally adapted to a different environment from the one in which it was developed and without losing its psychometric qualities for screening neurocognitive disorders in older adults. The results show that the 5WT is useful for discriminating between people with and without cognitive impairment.

In the case of major ND (dementia), the areas under the curve estimated by the different components of the $5 \mathrm{WT}$ are larger than those of the MMSE, which is a common global screening instrument, while its sensitivity and specificity are similar to those of previous studies (Croisile et al., 2007; Mormont, Jamart, \& Robaye, 2012). These areas are not statistically different from each other, however, suggesting that the $5 \mathrm{WT}$ alone is no more useful for screening for major ND than the MMSE. Nevertheless, using the 5 WT (with a cut-off point of $\leq 16 ; 89 \%$ sensitivity and $98 \%$ specificity) together with the MMSE (with a cut-off point of $\leq 24 ; 83 \%$ sensitivity, and $96 \%$ specificity) could be a strategy for increasing the diagnostic accuracy of major ND with neurodegenerative etiology (Alzheimer's disease) because the nature of the 5WT allows an analysis of the amnesic mechanisms that are only superficially explored by the MMSE.

Table 2

Optimum cut-off points, sensitivity and specificity of 5WT

\begin{tabular}{lccccccc}
\hline & \multicolumn{3}{c}{ CH vs Major ND } & & \multicolumn{3}{c}{ CH vs Minor ND } \\
\cline { 2 - 4 } \cline { 6 - 8 } & Cut-off point & Sensitivity & Specificity & & Cut-off point & Sensitivity & Specificity \\
\hline FRS & $\leq 7$ & $88.9 \%$ & $98.6 \%$ & & $\leq 6$ & $74.0 \%$ & $62.9 \%$ \\
TRS & $\leq 9$ & $80.6 \%$ & $98.6 \%$ & & $\leq 10$ & $56.2 \%$ & $84.3 \%$ \\
WTS & $\leq 16$ & $88.9 \%$ & $98.6 \%$ & & $\leq 18$ & $64.4 \%$ & $77.1 \%$ \\
\hline
\end{tabular}

Notes: $\mathrm{CH}$ :Cognitively healthy, ND:Neurocognitive disorder, FRS:Free recall score, TRS:Total recall score, WTS:Weighted total score. 
On the other hand, as in the study by Rozzini et al. (2017), the 5WT proved to be useful for identifying subjects with minor ND or mild cognitive impairment (MCI), albeit with lower sensitivity and specificity and area under the curve, which was .77 (95\% CI $[.70, .85])$ with a cut-off point of $\leq 18,66 \%$ sensitivity and $77 \%$ specificity, which can be attributed to the subtlety and heterogeneity of the cognitive alterations present in subjects with MCI. Accordingly, the use of such a screening tool could be insufficient for identifying minor ND due to the false positives it contains. However, when attempts have been made to analyze the various types of MCI (for example, single domain versus multiple domains; Bolívar \& Saladie, 2016), it has proved to discriminate between them.

Thus, the 5WT is a test that is valid for assessing verbal episodic memory, which is the specific element of amnesic cognitive impairment and is usually an initial clinical finding of the most frequent form of major degenerative ND (Alzheimer's disease). Consequently, poor performance in the 5WT would translate the functional disconnection of the hippocampus from neocortical regions (American Psychiatric Association, 2014; Dubois et al., 2010).

The 5WT appears to be a useful instrument for both clinical practice and research since, in addition to obtaining a score that makes it possible to discriminate different states of a patient's cognitive function, it also offers complementary qualitative elements (such as type of errors and dissociation between the performance of the various memory mechanisms), which could be used for subjective analysis and contribute to accuracy when establishing a clinical diagnosis. Although the educational attainment of the participants in this study was lower than that of the original French study (Dubois et al., 2002), the 5WT maintains its discriminative qualities.

However, this study has some limitations. Participants were recruited at a memory clinic of a single tertiary level health center, and those with a degenerative cognitive profile were selected, which excludes all the vascular or mixed forms of cognitive impairment also common in Mexico, suggesting a potential selection bias. Consequently, its results should be interpreted with caution when it is used as a screening tool in the general population. In addition, the inter- or intra-rater reliability of the 5WT was not evaluated in this study, which would have been desirable.

Despite its limitations, the present study offers the first Spanish validation and cultural adaptation of the 5WT, which will encourage its widespread use and therefore a better understanding of its qualities for screening for cognitive problems in older adults.

\section{Funding}

None.

\section{Conflict of interest}

The authors declare they have no conflicts of interest.

\section{Acknowledgements}

The authors are grateful to Dr. Juan Manuel Villalpando, Dr. Luis Miguel Gutiérrez Robledo and neuropsychologist Ma. Alejandra Samudio Cruz for their contributions in the generation of the study and the evaluation of the patients included in the study.

\section{REFERENCES}

Aguilar-Navarro, S. G., Mimenza-Alvarado, A. J., Samudio-Cruz, M. A., Hernández-Contreras, F. J., Gutiérrez-Gutiérrez, L. A., Ramírez-González, F., \& Avila-Funes, J. A. (2018). Validation of the Clock Drawing Test Scoring Method in older adults with neurocognitive disorder. Salud Mental, 41(4), 179-186.

American Psychiatric Association. (2014). Guía de consulta de los criterios diagnósticos del DSM-5 ${ }^{\circledR}$ : Spanish Edition of the Desk Reference to the Diagnostic Criteria From DSM-5 ${ }^{\circledR}$. American Psychiatric Pub.

Bolívar, J. C., \& Saladie, D. G. (2016). Redefining amnestic mild cognitive impairment as an early form of Alzheimer's disease based on assessment of memory systems. Journal of Alzheimer's Disease, 53(2), 705-712. doi: 10.3233/ JAD-160117

Bush, C., Kozak, J., \& Elmslie, T. (1997). Screening for cognitive impairment in the elderly. Canadian Family Physician, 43, 1763-1768.

Carley, S., Dosman, S., Jones, S. R., \& Harrison, M. (2005). Simple nomograms to calculate sample size in diagnostic studies. Emergency Medicine Journal, 22(3), 180-181. doi: 10.1136/emj.2003.011148

Consejo Nacional de Población. (2013). Proyecciones de la Población de México 2010-2050. Retrieved from https:/www.gob.mx/cms/uploads/attachment/ file/63977/Documento_Metodologico_Proyecciones_Mexico_2010_2050.pdf

Croisile, B., Astier, J. L., \& Beaumont, C. (2007). Étalonnage du test des cinq mots dans une population de sujets sains. Revue Neurologique, 163(3), 323-333. doi: 10.1016/S0035-3787(07)90404-X

Doraiswamy, P. M., Steffens, D. C., Pitchumoni, S., \& Tabrizi, S. (1998). Early recognition of Alzheimer's disease: what is consensual? What is controversial? What is practical?. The Journal of Clinical Psychiatry, 59(Suppl 13), 6-18.

Dubois, B., Feldman, H. H., Jacova, C., Cummings, J. L., DeKosky, S. T., BarbergerGateau, P., ... Gauthier, S. (2010). Revising the definition of Alzheimer's disease: a new lexicon. The Lancet Neurology, 9(11), 1118-1127. doi: 10.1016/ S1474-4422(10)70223-4

Dubois, B., Touchon, J., Portet, F., Ousset, P. J., Vellas, B., \& Michel, B. (2002). The 5 words: A simple and sensitive test for the diagnosis of Alzheimer's disease. Presse Médicale, 31(36), 1696-1699.

Eknoyan, D., Hurley, R. A., \& Taber, K. H. (2012). The clock drawing task: common errors and functional neuroanatomy. The Journal of Neuropsychiatry and Clinical Neurosciences, 24(3), 260-265. doi: 10.1176/appi.neuropsych.12070180

Folstein, M. F., Folstein, S. E., \& McHugh, P. R. (1975). Mini-mental state: A practical method for grading the cognitive state of patients for the clinician. Journal of Psychiatric Research, 12(3), 189-198. doi: 10.1016/00223956(75)90026-6. Retrieved from http://home.uchicago.edu/ tmurray1/ research/articles/printed $\% 20$ and $\% 20 \mathrm{read} / \mathrm{mini} \% 20$ mental $\% 20$ state_a $\% 20$ practical $\% 20$ method $\% 20$ for $\% 20$ grading $\% 20$ the $\% 20$ cognitive $\% 20$ state $\% 20$ of $\% 20$ patients $\% 20$ for $\% 20$ the $\% 20$ clinician.pdf

Grober, E., Buschke, H., Crystal, H., Bang, S., \& Dresner, R. (1988). Screening for dementia by memory testing. Neurology, 38(6), 900-903. doi: 10.1212/ WNL.38.6.900

Grober, E., Mowrey, W. B., Ehrlich, A. R., Mabie, P., Hahn, S., \& Lipton, R. B. (2016). Two-stage screening for early dementia in primary care. Journal of Clinical and Experimental Neuropsychology, 38(9), 1038-1049. doi: $10.1080 / 13803395.2016 .1187117$

Katz, S., \& Akpom, C. A. (1976). 12. Index of ADL. Medical Care, 14(Suppl 5), 116 118. doi: 10.1097/00005650-197605001-00018

Lawton, M. P., \& Brody, E. M. (1969). Assessment of older people: self-maintaining and instrumental activities of daily living. The Gerontologist, 9(3), 179186. doi: 10.1093/geront/9.3_Part_1.179. Retrieved from http://www. 
eurohex.eu/bibliography/pdf/Lawton_Gerontol_1969-1502121986/Lawton Gerontol_1969.pdf

McKhann, G., Drachman, D., Folstein, M., Katzman, R., Price, D., \& Stadlan, E. M. (1984). Clinical diagnosis of Alzheimer's disease: Report of the NINCDSADRDA Work Group under the auspices of Department of Health and Human Services Task Force on Alzheimer's Disease. Neurology, 34(7), 939-939. doi: 10.1212/WNL.34.7.939

Mejía-Arango, S., Miguel-Jaimes, A., Villa, A., Ruiz-Arregui, L., \& GutiérrezRobledo, L. M. (2007). Cognitive impairment and associated factors in older adults in Mexico. Salud Pública de México, 49(4), 475-481.

Mejía-Arango, S., \& Gutierrez-Robledo, L. M. (2011) Prevalence and incidence rates of dementia and cognitive impairment no dementia in the Mexican population: data from the Mexican Health and Aging Study. Journal of Aging and Health, 23(7), 1050-1074. doi: 10.1177/0898264311421199

Mormont, E., Jamart, J., \& Robaye, L. (2012). Validity of the five-word test for the evaluation of verbal episodic memory and dementia in a memory clinic setting. Journal of Geriatric Psychiatry and Neurology, 25(2), 78-84. doi: $10.1177 / 0891988712445088$

Morris, J. C. (1993). The Clinical Dementia Rating (CDR): current version and scoring rules. Neurology, 43(11), 2412-2414. doi: 10.1212/wnl.43.11.2412-a. Retrieved from https://s3.amazonaws.com/academia.edu.documents/60763437/ CDR_verdadero20191001-70149-1hobqo2.pdf?response-contentdisposition=inline $\% 3 \mathrm{~B} \% 20$ filename $\% 3$ Dscoring rules_The_Clinical Dementia_Rati.pdf\&X-Amz-Algorithm=AWS4-HMAC-SHA256\&XAmz-Credential=AKIAIWOWYYGZ2Y53UL3A\%2F20191212\%2F us-east-1\%2Fs3\%2Faws4_request\&X-Amz-Date=20191212T024021Z\&XAmz-Expires $=3600 \& X-A m z-$ SignedHeaders $=$ host $\& X-A m z-$ Signature $=3 \mathrm{~d} 946$ 6c95b3815e997c1e0b68805a223d08d2c8d0f2667b3451f2fb974c89df2

Navarrete, H., \& Rodríguez-Leyva, I. (2003). La demencia ¿Subdiagnosticada o ignorada?. Revista Mexicana de Neurociencias, 4, 11-12. Retrieved from http://
previous.revmexneurociencia.com/wp-content/uploads/2014/07/Nm0031-02. pdf

Organización Panamericana de la Salud. (2001). Encuesta de Salud y Envejecimiento de Latinoamérica. Retrieved from http://envejecimiento.csic.es/documentos/ documentos/paho-salud-01.pdf

Prince M., Acosta D., Ferri C. P., Guerra M., Huang Y., Llibre Rodriguez J. J. L., ... Liu Z. (2012). Dementia incidence and mortality in middle income countries, and associations with indicators of cognitive reserve: a 10/66 Dementia Research Group population-based cohort study. Lancet, 380(9836), 50-58. doi: 10.1016/S0140-6736(12)60399-7

Rodriguez, J. J. L., Ferri, C. P., Acosta, D., Guerra, M., Huang, Y., Jacob, K. S., ... Prince, M. E. (2008). Prevalence of dementia in Latin America, India, and China: a population-based cross-sectional survey. The Lancet, 372(9637), 464474. doi: 10.1016/S0140-6736(08)61002-8

Rozzini, L., Ceraso, A., Zanetti, M., Pelizzari, S., Tomasoni, E., Accardo, V., \& Padovani, A. (2017). The Italian version of the five-word test: A simple diagnostic test for Dementia due to Alzheimer's Disease in routine clinical practice. Behavioural Neurology, 9, 1-6. doi: 10.1155/2017/3781407

Sheikh, J. I., \& Yesavage, J. A. (1986). Geriatric Depression Scale (GDS): recent evidence and development of a shorter version. Clinical Gerontologist: The Journal of Aging and Mental Health, 5(1-2), 165-173. doi: 10.1300/ J018v05n01_09

Wong, R., Espinoza, M., \& Palloni, A. (2007). Adultos mayores mexicanos en contexto socioeconómico amplio: salud y envejecimiento. Salud Pública de México, 49(S4), 436-447.

Wong, R., Michaels-Obregon, A., \& Palloni, A. (2015). Cohort profile: the Mexican health and aging study (MHAS). International Journal of Epidemiology, 46(2), e2-e2. doi: 10.1093/ije/dyu263 